logical (Non-Medical) Problems of Nuclear Physics, under Lord Rothschild's chairmanship, is responsible for oversight of this monitoring, and it has set up a special sub-committee under Dr. J. F. Loutit, director of the Medical Research Council Radiobiological Research Unit. Mr. Macmillan said that he is satisfied that it is right to proceed with the further tests at Christmas Island.

\section{Observations on the Russian Satellite}

A MeEting of the Royal Society will be held on November 29, beginning at 10.30 a.m., when Prof. H. S. W. Massey will open a discussion. on "Observa. tions of the Russian Artificial Earth Satellite and their Analysis" ; the discussion will continue throughout the day.

An additional meeting of the Radio and Telecommunication Section of the Institution of Electrical Engineers has been arranged to be held on November 22, when there will be a discussion on "Radio Observations on the Russian Satellite". A number of short contributions will be presented by members of the various establishments in Britain who have been making observations. These contributions will describe the part which radio is playing in observing the behaviour of the first satellite and the subject will be divided into the following five sections : interferometer determinations; direction finding; Doppler determinations ; signal characteristics; radar determinations. The meeting will commence with an afternoon session from 2.30 to 4.30 p.m., to be followed by tea and an evening session starting at 5.30 p.m. Further information can be obtained from the Secretary, Institution of Electrical Engineers, Savoy Place, London, W.C.2.

\section{British Computer Society, Ltd.}

More than two hundred members attended the first meeting on October 21 of the British Computer Society, Ltd., held at the MacMillan Hall of the University of London. Prof. D. R. Hartree, under the title of "The Machine's-Eye View", gave examples of errors that can occur in computing processes. $\mathrm{H}_{\Theta}$ made two points; first, in a hand computation an intelligent and experienced computer will often exereise that intelligence, and intuition, based on experience, about the sort of way in which the calculations are likely to go; whereas the machine is an approximation to an unintelligent and inexperienced computer, and has not got this background of knowledge and experience unless it is explicitly built into the programme. His second point was made on behalf of the machines, emphasizing that machine errors are not the only sources of wrong results. Such errors may also occur through the machine being supplied with the wrong data, through programme errors, or through use of a programme which carries out, however correctly, a process which is unsuitable for obtaining the results required. It is essential for the user of the machine to understand not only how to programme but also what to programme.

\section{Process for Crease-fixed Wool}

The success of wool/'Terylene' fabrics in providing durable pleats in skirts and creases in trousers has revealed the large consumer demand that exists for garments with these properties. The problem of providing such stable creases is that of obtaining a permanent set in the fibres that compose the fabric. Wool can be permanently set by a number of chemical processes, and attempts have been made to use these in providing durable creases in all-wool fabrics. The difficulty has been to obtain one that was commercially attractive. The Commonwealth Scientific and Industrial Research Organization (Australia) now reports that the method based on thioglycollic acid can provide durable creases in allwool materials. The method has the advantage of simplicity in commercial application.

University News : The Queen's University, Belfast

THE following appointments in The Queen's University of Belfast have recently been made: Dr. J. C. West, to the chair of electrical engineering: Dr. J. Pemberton, to the chair of social and preventive medicine; Dr. L. W. Kerr, to be lecturer in physies; Dr. I. C. Roddie and Mr. E. W. Clarke, to be lecturers in physiology; and Dr. J. W. Dundee, to be lecturer in anæesthetics.

\section{Announcements}

At the annual general meeting of the Association of Clinical Biochemists, held recently at the Royal College of Surgeons, London, the following officers were elected : President, Prof. E. J. King ; Chairman, Dr. R. Gaddie; Hon. Treasurer, Dr. J. H. Wilkinson ; Hon. Secretary, Dr. A. L. Tárnoky (Royal Berkshire, Hospital, Reading).

THE latest date for submission of applications for research fellowships in psychiatry, psychology, sociology, neurophysiology, and other sciences relevant to mental health, offered by the Foundations' Fund for Researeh in Psychiatry, is February 1, 1958. Further details may be obtained from Foundations' Fund for Research in Psychiatry, 251 Edwards Street, New Haven, 11, Connecticut.

Optica Acta and Acta Electronica have undertaken the joint publication of the full proceedings of the international symposium on the physical problems of colour television held in Paris last July. Inquiries can be addressed to Optica Acta, 3 Boulevard Pasteur,

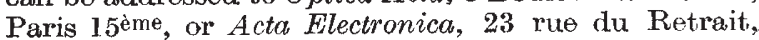
Paris $\mathrm{XX}^{0}$.

The Institution of Chemical Engineers has joined the European Federation of Chemical Engineering, the object of which is "the furthering of European co-operation in the field of chemical engineering, which includes chemical apparatus and equipment, chemical process technology, materials as applied in the industry, and basic chemical operations." The European Federation of Chemical Engineering now has the following Secretariats: Deutsche Gesellschaft für Chemisches Appatewesen, in Frankfurt am Main; the Institution of Chemical Engineers, in London; and Société de Chimie Industrielle, in Paris.

Erratum. In the communication entitled "Adiabatic Piezo-Optic Coefficient of Heavy Water", by C. K. Narayanaswamy, P. S. Narayanan and R. S. Krishnan (Nature, 180, 497; 1957), the phrase ". . . carbon disulphide, a highly polar liquid" occurring near the end of column 1, p. 498, should read ". . . carbon disulphide, a highly anisotropic liquid". 